\title{
Bile duct injury following laparoscopic cholecystectomy in a patient with situs inversus
}

\author{
Sertaç Usta, Koray Karabulut \\ Department of General Surgery, Fırat University Faculty of Medicine, Elazığ, Turkey
}

To the Editor;

Currently there is no report in English literature, about bile duct injury during a laparoscopic cholecystectomy in patients with situs inversus. We have decided to report a patient, with situs inversus, who was referred to our hospital after a bile duct injury during a laparoscopic cholecystectomy.

The patient was a 61 year old man, who experienced jaundice and abdominal pain. After a previous laparoscopic converted to open cholecystectomy 5 days before his admission to our hospital. His vital parameters were normal. He had jaundice and a left paramedian incision upon physical examination. The total bilirubin level was $14.4 \mathrm{mg} / \mathrm{dL}$ and direct biluribin was $7.5 \mathrm{mg} / \mathrm{dL}$. A chest radiograph showed dextrocardia, confirming the presence of situs inversus. Magnetic resonance cholangiopancreatography (MRCP) revealed a Strasberg Type E2 bile duct ligation. Percutaneous transhepatic biliary drainage was also performed and the cholangiogram confirmed the MRCP findings. After one month of follow-up, he underwent a laparotomy and hepaticojejunostomy. The postoperative period fort his final surgery was uneventful and he was discharged home on the postoperative $6^{\text {th }}$ day.

Situs inversus totalis is a rare autosomal recessive disor- der with an incidence of 1 in 5000 to 20.000 live births. ${ }^{[1]}$ Diagnosis of gallstone disease in patients with situs inversus is difficult, especially in those with an unknown history of this condition. ${ }^{[2]}$ Because of the eccentric anatomy of the left-sided gallbladder, the clinical presentation of these patients usually involves left upper-quadrant pain; however, 30\% of patients reportedly develop epigastrium pain, including this patient. Approximately $10 \%$ of patients complain of right upper-quadrant pain, which is a classic presentation in patients without situs inversus. ${ }^{[2]}$ Clinical features and routine presurgical imaging including ultrasonography (US) could miss the anomalous position, there by producing complications during surgery. ${ }^{[3]}$

Since the first published paper of left-sided position of the gallbladder in 1886, less than 150 cases have been reported in the literature. ${ }^{[3]}$ These articles tell us that, laparoscopic cholecystectomy in patients with a left-sided gallbladder is not often confidently performed by righthanded surgeons because of the unusual orientation. ${ }^{[1-5]}$ However, none of these articles report any biliary injury after laparoscopic cholecystectomy. This may be due to surgeons giving more attention than usual in this kind of operation or perhaps they do not report bile duct injuries for these cases.

Conflict of Interest: None declared. 


\section{References}

1. Rungsakulkij N, Tangtawee P. Fluorescence cholangiography during laparoscopic cholecystectomy in a patient with situs inversus totalis: a case report and literature review. BMC Surg 2017;17:43. [CrossRef]

2. Deguchi Y, Mitamura K, Omotaka S, Eguchi J, Sakuma D, Sato $M$, et al. Single-incision cholecystectomy in a patient with situs inversus totalis presenting with cholelithiasis: A case report. Asian J Endosc Surg 2015;8:347-9. [CrossRef]

3. Abongwa HK, De Simone B, Alberici L, laria M, Perrone G,
Tarasconi A, et al. Implications of Left-sided Gallbladder in the Emergency Setting: Retrospective Review and Top Tips for Safe Laparoscopic Cholecystectomy. Surg Laparosc Endosc Percutan Tech 2017;27:220-7. [CrossRef]

4. Phothong N, Akaraviputh T, Chinswangwatanakul V, Trakarnsanga A. Simplified technique of laparoscopic cholecystectomy in a patient with situs inversus: a case report and review of techniques. BMC Surg 2015;15:23. [CrossRef]

5. Raghuveer MN, Mahesh Shetty S, Sunil Kumar BB. Laparoscopic Cholecystectomy in Situs Inversus Totalis. J Clin Diagn Res 2014;8:ND03-ND05. 